\title{
The effect of relations holding between verbal and visual components in advertising language
}

\author{
By
}

\author{
Ahmed SAyed Abdelhay* \\ ahmed.abdelhai@sadatacademy.edu.eg
}

\begin{abstract}
Visuals have their own linguistic system that enables people to construct their meaning process. An image is used in advertising as a reflection or representation of life. It may stand alone or unite with other elements to present an argument that inform or persuade a target audience. Both visual and other elements have a link or a relation that hold between them. The present study examines relations holding between the verbal and visual components of the advertisements. Results have shown that advertisers tend to establish certain relations between parts of an advertisement in order to enforce certain effects on the advertisement. Verbal and visual elements unite together to complete a meaning and for posing a persuasive effect
\end{abstract}

Keywords: relations. Verbal. Visual. Rhetoric. Advertising. Persuasion.

\section{Introduction:}

We are surrounded with commercial messages at every point of the day in radio, on billboards, in magazines and newspapers, and on TV. Today people are surrounded by a world of spectacular visuals; they see images more than words (Brierley, 1995). According to Alozie (2010),

* Assistant Lecturer in Linguistics, Department OF

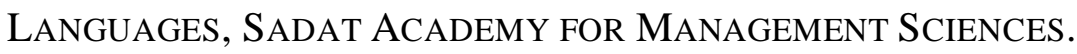

( The effect of relations holding ...) Dr. AHMED ABDELHAY 
advertising is a vehicle for marketing products across cultures. It also serves as a medium for conveying rhetorical, symbolic, and metaphorical contents. Advertising depends on using multimodality such as visual imagery, colors, and other non-verbal elements to convey and enforce cultural values.

An advertisement as "a paid-for communication intended to inform and/or persuade one or more people" (Fletcher, 2010, p. 2). In other words, an advertisement is an intended communication bridge between the sender and the receiver. Advertisements communicate something in words, pictures, or both to inform and/or persuade the target audience. Thus, pictures are texts made of signs. There is a debate on the significance of advertising whether it is intended to inform or to persuade. It is difficult to state the purpose of advertising; however, an advertisement presents information for the purpose of persuasion. Advertisements are informative persuasive communication. Advertisements that do not persuade can hardly be described as advertisements.

Visuals have their own linguistic system that enables people to construct their meaning process. An image is used in advertising as a reflection or representation of life. It may 
stand alone or unite with other elements to present an argument that inform or persuade a target audience. According to Kress and Van Leeuwen (1996), verbal and visual structures express meanings; visual structures are interpreted according to the common cultural sources, experiences, and social interactions of a society.

Goodman and Messaris (as cited in Wang and Peracchio, 2008) stated that advertisers are used to using visual rhetoric in print advertisement. Goodman (2002, p. 37) stated that "As the initial point of interest, the image must also be presented in ways that pull the reader deeper into the ad". Thus, advertisers are encouraged to employ visual images for the purpose of creating effective advertising and persuading viewers of an advertisement. The present study is intended to test the impact of using verbal and visual elements in advertising on consumers' response.

Many disciplines and areas of study- such as sociosemiotics, visual communication, and rhetorical approaches to advertising and visual persuasion- are now trying to understand how combinations of words and pictures work (Bateman, 2014). From a semiotic point of view, McQuarrie and Mick (2003) drew attention to the relation between sign 
and text in advertising stating that a sign is anything that can stand for something else, while a text refers to any purposeful linguistic or pictorial collection of signs.

Bateman (2014) argued that the text plays a central role directing the reader towards a pre-chosen meaning causing the reader to avoid some meanings and consider others; while the image captures the readers' attention and presents some additional details. However, many relations can hold between text-image combinations. When words explain images making them clear and elucidating one of the possible meanings of the image, the relation holding is elaboration or anchorage.

\section{Significance of the Study:}

The present study aims at helping understand the language of advertising as well as the tools that advertisers use to communicate their. It also explores the structures of advertisements and the relations holding between their parts

\section{Research Questions:}

The study is intended to answer three main questions. Firstly, how do advertisers relate parts of the advertisements to each other? Secondly, what are the relations that hold 
مجلة كلية الآداب جامعة الفيوم (اللغويات والثقافات المقارنة) مجج 13، ع 2 (يوليو) 2021

between parts of the advertisements and what are their functions? And finally, what is the relation between verbal and visual parts in the selected advertisements?

\section{Hypotheses:}

The present study tests the following three hypotheses. Firstly, advertising directs consumers to perform an action set in advance by the advertiser. Secondly, advertisers establish relations between the parts of an advertisement. And finally, some elements of the advertisements are central to the message delivered; others are secondary.

\section{Theoretical framework:}

For the purpose of the analysis, the study adopts Mann and Thompson's (1988) rhetorical structure theory (RST) and the semiotics doctrine.

\subsection{Mann and Thompson's (1988) (RST):}

\subsubsection{Introduction:}

Rhetorical Structure Theory (RST) is a descriptive linguistic theory of discourse organization. It is concerned with text organization, and it is used to show text coherence and analyze the structure of texts. It is a theory of how texts 
work; it shows relations between parts of a text. RST was first developed in the 1980s at the Information Science Institute of the University of South California by a group of researchers interested in Natural Language Generation, William Mann, Christian Matthiessen, and Sandra Thompson, with input from Cecilia Ford, Barbara Fox, and Peter Fries.

RST is interested in how written texts function, and how they involve linguistic entities such as words, phrases or grammatical structures. It is a tool that could be applied to several linguistic situations and applications. It enables the analyst (observer or judge) to systematically annotate every part of the text. RST analysis has been applied to different types of texts, such as magazine articles, administrative memos, advertisements and more. These analyses outcomes proved that many types of texts have an RST analysis; however, texts such as contracts, laws, and texts which include some poetry do not have. It identifies relations that hold between parts of the text to describe and characterize natural texts structures primarily in terms of the identified relations. 
Understanding RST structures and relations is important to understanding the text. Relations help recognize assertional relational forms. They convey relational propositions that have assertional effects so that people can understand relational propositions; even though morphosyntactic signals of the text do not exist. Relational propositions are important to the coherence of the text. Texts with no relational propositions are coherently broken, and have alternative interpretation. The communicative effect of relational propositions is not explicit in the text, and is equal to the meanings of its sentences, and those meanings are composed from the text syntactic structures and lexical meanings. Relational propositions are derived from the relation definition, in particular, the effect field.

According to Taboada and Mann (2006) and Taboada and Stede (2009), these relations are also called rhetorical relations, discourse relations, coherence relations or conjunctive relations. RST addresses coherence through a hierarchical structure of texts according to the role and function of each part with respect to the other parts of the text. To analyze a text, the reader reads the text, breaks it into units or text spans and establishes a diagram. Adding an RST 
relation to the diagram connects units to each other. This diagrammatic representation of relations is referred to as schemas.

\subsubsection{Definitions for relations, schemas and structures}

There are four kinds of RST defined objects: relations; schemas; schema applications; and structures.

\section{i. Relations}

Relations are the particular relationships that can be found between two spans (parts) of a text. They identify the relationships that hold between two spans of a text. Relations holding between two non-overlapping text spans are either called nucleus $(N)$ or satellite $(S)$. A nucleus is the most central part or span of the text; a satellite is the secondary part or span to the text. According to Taboada and Mann (2006) and Taboada and Stede (2009), each relation is defined in terms of four fields:

a) Constraints on the nucleus,

b) Constraints on the satellite,

c) Constraints on the combination of Nucleus and Satellite,

d) The effect. 
These fields help the analyst to make particular judgments, plausible rather than certain, in building RST structures. The analyst accesses the text, knows about its context, judges the writer (W) or the readers (R), and shares their cultural conventions. The Effect field is an essential part of a relation definition. It is the condition achieved through the use of the relation. In the analysis, the effect serves as a constraint against unsuitable uses of the relation. Every judgment, in effect, for example, is of the form 'It is plausible to the analyst that.......' All judgments are based on the text, and thus from the writer's point of view.

Mann and Thompson (1988, p. 246) define an antithesis relation, for example, as 'It is plausible to the analyst that it is plausible to the writer that comprehending $\mathrm{S}$ and the incompatibility between $\mathrm{N}$ and $\mathrm{S}$ would increase R's positive regard for N'. The analyst must go beyond the text in order to judge the text functions. He/she has to provide plausible reasons to identify the claims underlying the relation of each part to the text as a whole.

Another example is an evidence relation. The first field means that the reader may not find $\mathrm{N}$ believable to a degree satisfactory to the writer. The second field shows that the 
reader believes $\mathrm{S}$ or will find it credible. The third field means that as a result of comprehending $\mathrm{S}$, the reader's belief of $\mathrm{N}$ is increased. Finally, the fourth filed means that the reader believes $\mathrm{N}$.

\section{ii. Schemas}

Schemas define how text spans are structurally arranged, and how they co-occur. In addition, they show the relationship between a span to other spans of the text. Schemas consist of a few constituent text spans, specifying the relations between them, and the relation of certain spans (nuclei) to the whole collection.

Schemas, then, specify how text spans can happen together. Schemas and schema application conditions are responsible for the possible of an RST structure. RST presents five kinds of schemas, represented below by (Mann and Thompson, 1988):

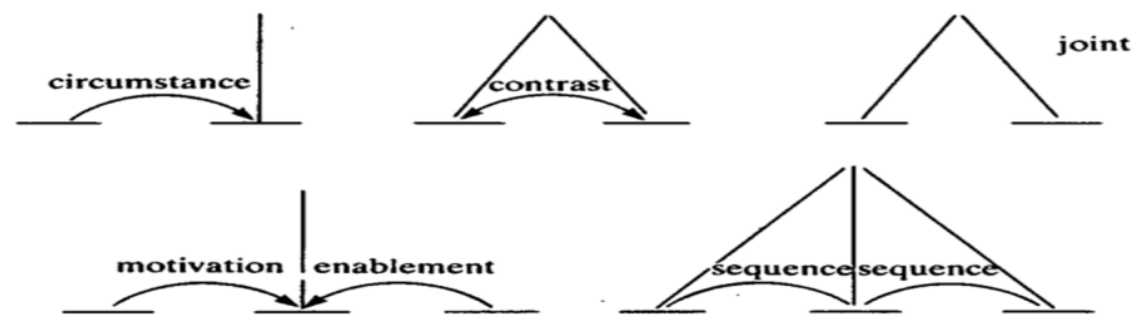

Figure 1: the five schemas types

( The effect of relations holding ...) Dr. AHMED ABDELHAY 
The curves represent relations holding between spans; vertical lines represent and identify the nuclear spans; and horizontal lines stand for a span or spans of a text. Other patterns with a single relation that are not mentioned in the figure are represented by Circumstance, a single relation with nucleus and satellite. Mann and Thompson (1988, p. 247) stated that 'the large majority of both schemas and schema applications follow this simple pattern'. In other words, relations are of two types: (a) hypotactic (mononuclear) having one span, nucleus, more salient than the other, satellite; and (b) paratactic (multi-nuclear) having all spans equally important.

\section{iii. Schema application}

It is possible for Schemas application to differ from the schemas as defined. Applications of a schema are determined by three conventions:

a) Unordered spans: the order of nucleus or satellites is not constrained by schemas.

b) Optional relations: all individual relations in multi-relation schemas are optional; however, one relation at least must hold. 
c) Repeated relations: a relation which is part of a certain schema can be applied many times in its application.

\section{iv. Structural analyses and structure diagrams}

Structures define the way schema applications are composed. An RST analysis divides the text, based on a theory-neutral classification, into units. In other words, units should have independent functional integrity. Units are clauses, however, 'clausal subjects and complements and restrictive relative clauses are considered as parts of their host clause unit rather than as separate units' (Mann and Thompson, 1988, p.248).

\subsubsection{Effects and functionalism}

The Effect field is an essential part of a relation definition. It is the condition achieved through the use of the relation. In the analysis, the effect serves as a constraint against unsuitable uses of the relation. This leads to the following conclusion about RST structural descriptions of texts: The definition for each relation and schema definition applies only when the analyst believes that the writer achieved the effect through using the spanned portion of the text. Thus, 
the analyst is trying plausibly to account for the writer's intention of the text. It becomes clear, then, that the analysis is a functional account of the text that produces a desired effect on the reader intended by the writer. The analyst states that each effect is plausible according to the relation definition. The analysis depends on structures of functions instead of structures of form.

\subsubsection{Nuclearity:}

As mentioned earlier, RST divides texts into minimal units or pairs of spans. These units or spans are of two different types, "Nuclei" and "Satellites". "Nuclei" are the most important and central parts of a text. The nucleus presents the basic information and reveals the writer's intention and purpose. Without a nucleus the text would be incomprehensible. On the other hand, "Satellites" are secondary to the "Nuclei". The satellite is often incomprehensible alone. By itself, a satellite cannot express the writer's intentions.

Both a nucleus and a satellite are related to each other. The relations (mostly asymmetric) are the relationship that holds between the members of these pairs. However, there 
are commonalities among the parts of spans if the asymmetries were arranged in a particular way, in effect for example. There are three commonalities that could be noticed:

i. Often, one of the pair members is only understood depending on the other, but not vice versa, a nonsequitur. The background satellite is a non-sequitur without the unclear span it illuminates.

ii. Often, one member can be largely substituted more than the other. An evidence satellite can be substituted by different evidence without changing the function of the whole text.

iii. Often, one of the members is more central to the writer's intention than the other.

'These asymmetries form a single pattern which is represented in the relations definitions by the assignment of the nucleus and satellite labels' (Mann and Thompson, 1988, p. 266). In the analysis of a text, identifying a nucleus is a result of recognizing that a particular relation holds. 


\subsection{Semiotics}

\subsubsection{Definition}

Semiotics is a science with two fathers. Ferfinand de Saussure and C.S. Peirce. Both of them contributed to the development and evolution of semiotics. According to Saussure (as cited in Pritchard, 2000), semiotics is the science of signs in society. It is a linguistic tool for meaning inquiry that is applied to mass communication phenomenon. Pierce defined semiotics as "something in someone's mind that stands for something else". According to Danesi (2004), the term "semiotics" is derived from the Greek "semeion" means "mark" or "sign".

Danesi (2004) argues that a sign could be a color, a gesture, a wink, etc. in other words, a sign is anything that stands for something other than itself. For example, the word red qualifies a sign because it stands for a certain color. According to Sebeok (2001), a sign is any physical form that stands for an object and has a referent. Aristotle (as cited in Sebeok, 2001, p. 4) defined the sign as consisting of three dimensions: (1) the physical part of the sign itself (e.g., the sounds that make up the word cat); (2) the referent to which 
it calls attention (a certain category of feline mammal); and (3) its evocation of a meaning (what the referent entails psychologically and socially).

Building on the definition that a sign is any physical form that stands for an object and has a referent, Sebeok (2001) argues that signs of all types are recognizable as such because they have certain predictable and regular properties or structures. For example, most human signs have the capacity to encode two primary kinds of referents denotative and connotative, depending on usage and situation. Eco (as cited in Norrick, 1981, p. 22) defines the sign as "something which stands to somebody for something in some respect or capacity"

Akpan, Akpan, and Obukoadata (2013) studied the communicative values of symbols in print advertisements copies of selected Nigerian products. They also examined the relative influence of symbolic interpretations on consumers purchase decisions as well as the implications of such influence on product marketing. The study concluded that semiological inputs in advertising and marketing are extant and relevant to contemporary promotional strategies. The study made a strong recommendation for the inclusion of 
semiotic appraisals as a component of advertising effectiveness test during campaigns.

Dicerto (2018) argues that semiotics is concerned with studying how different modes are organized, what similarities and differences, and the abilities of meaningmaking. Chandler (2007) argues that semiotics studies anything that refers to something else. According to Dicerto (2018), sounds and images are used, just like language, to create independent texts. Texts combining at least two of the verbal, visual semiotic systems may be defined as multimodal.

\subsubsection{Characteristics of signs}

Saussure (as cited in Yakin and Totu, 2014 and Džanić, 2013) propose that a sign consists of two components, a signifier and a signified. A signifier is the abstract and physical material of the meaning. It is the vehicle of the meaning; while a signified is the mental construct which the signifier creates, the actual meaning to be conveyed.

According to Peirce (as cited in Dicerto, 2018), a sign is divided into three categories: icon, index, and symbol. 
Icons signify by resemblance. They resemble their signifieds and imitate them in some way sharing some qualities of the signifieds themselves. Indices are either physically or causally in direct connection with their signifieds. Symbols signify be invention. They have an arbitrary relation with their signifieds. The relation between them is conventionally established, only convention ties them together.

\section{Methodology:}

Procedures: First, the advertisements are verbally and visually analyzed to find out the rhetorical figures used. Then they are analyzed according to RST in order to find relations holding between their parts. The analysis decides the most significant part of the text to be a nucleus; and the secondary part to be a satellite. Then the analysis investigates a certain pre-established, based on the writer's intention that $\mathrm{s} /$ he supposed to communicate, relation holding between parts of the advertisement. 


\section{Analysis of the selected advertisements:}

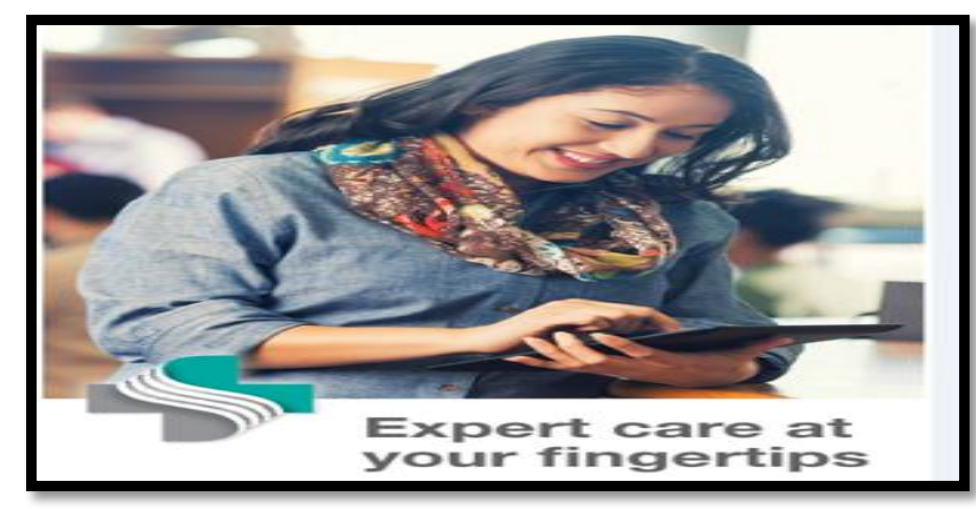

Figure (1)

On the verbal level, Figure (1) is an advertisement for Shutter Health, a medical foundation that provides online medical services. It reads "Expert care at your fingertips". It is plausible that the producer of the advertisement wants to say that it is very easy to get medical services by clicking using your fingertips. The advertisement tries to persuade through highlighting the easiness of using and getting medical services offered by the foundation to the reader its services wherever s/he is. The word fingertips could have two senses: (a) clicking using your fingertips, and (b) easy and immediate availability for you; thus the advertisement is an example of homonym, an example of Trope.

( The effect of relations holding ...) Dr. AHMED ABDELHAY 
The advertisement consists of one clause, "Expert care at your fingertips". This span presents intraclausal relation representing two spans: 1) expert care, denoting that the foundation offers distinguished services and experts; and 2) at your fingertips, denoting the easiness of getting the services. The first span is the satellite; the second is the nucleus. Since the reader won't be able to understand the nucleus before reading the satellite, and the satellite increases the reader's ability to comprehend the nucleus, there is a background relation holding between the parts of the span.

On the visual level, the producer uses a picture of a young lady happily holding her tablet and getting online medical help. The use of her fingertips signifies the easiness with which she gets the service even if she is outside. There is a visual metaphor depicting a tablet as an expert. There is an iconic representation of the smart device and fingertips, indexical relation between fingertips and the internet; symbolic relation between internet and accessibility.

The visual part of the advertisement increases the reader's ability to perform the action or the argument presented in the verbal part. Accordingly, there is an 
enablement relation holding between the pictorial and verbal components of the advertisement.

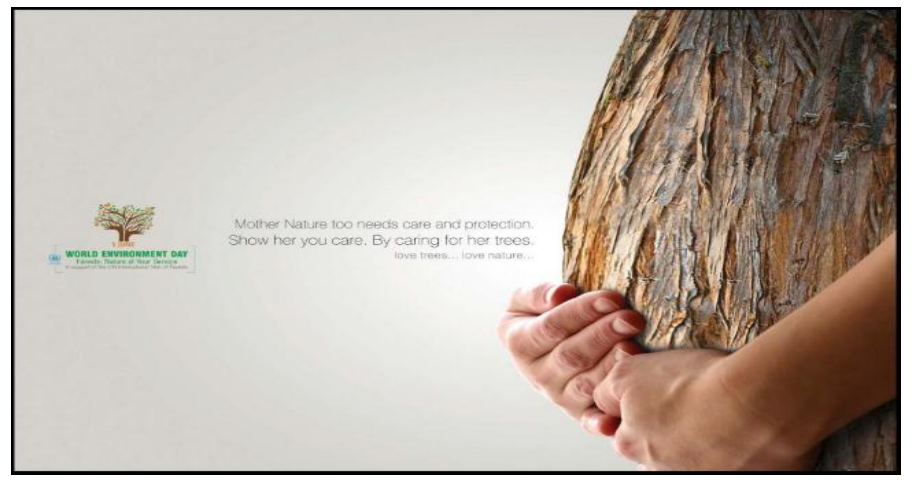

Figure (2)

On the verbal level, figure (2), an advertisement for World Environment Day association concerned with caring for nature, reads "Mother Nature too needs care and protection. Show her you care. By caring for her trees". It is plausible that the producer wants to tell the readers to care for and look after nature. He depicts nature as a pregnant woman and trees as her children who need care and protection. This advertisement is an example of metaphor, a trope.

The advertisement consists of three spans: 1) Mother Nature too needs care and protection; 2) Show her you care; 3) By caring for her trees. The first span is positioned in the 
upper part of the advertisement thus it is a nucleus; while the second and third spans are positioned below the first span. However, it is plausible that the third span is more central, a nucleus, to the advertiser's intent, while the first and second spans are less important, satellites. Since performing the action presented in the nucleus depends on comprehending the satellite, there is an enablement relation holding between the first span and the other two spans. Moreover, the third span presents a method which makes the realization of the nucleus in the first span more likely, thus there is a means relationship between the third span and the second span.

On the visual level, the producer used a visual metaphor to depict a tree as a pregnant woman putting her hands on her swelled belly. The advertisement wants to say that nature needs help, care, and protection just as a pregnant woman needs, and that trees need care and protection just like fetuses and infants need. There is an iconic representation of a swelled belly and pregnancy; an indexical relation between pregnancy and care; a symbolic relation between a swelled belly and pregnancy.

However the potential or apparent incompatibility between the visual and verbal components of the 
advertisement, the reader's recognition of compatibility between them increases his/her positive regard to accept the argument. Accordingly, there is a concession relation holding between the visual and verbal components of the advertisement.

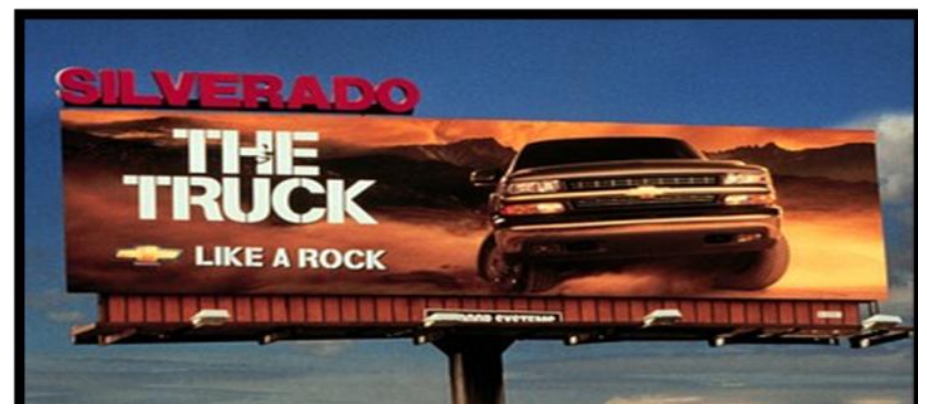

Figure (3)

On the verbal level, figure (3), an advertisement for Chevrolet cars, reads "THE TRUCK. LIKE A ROCK". This advertisement is an example of rhyme where a sound is repeated at the end of syllables. Rhyme is an example of scheme. It is plausible that the producer wants to tell the audiences that their vehicles are very strong like a rock and that you can drive them in unpaved ways.

The advertisement could be divided into two spans: 1) the truck; 2) like a rock. The first span is written in a large bold font and positioned in the top of the advertisement, a 
nucleus; while the second span is a smaller font and positioned in the lower part, a satellite. The satellite presents additional details about the subject matter presented in the nucleus, thus there is an elaboration relation holding between the two spans.

On the visual level, the advertisement presents the picture of the advertised truck in a way that shows its powerful and strong capabilities on the road, in particular rocky roads. There is a simile that likens a truck to a rock. There is an iconic representation of rocks and the truck; an indexical relation between rocks and heavy-duty trucks; a symbolic relation between rocks and strength.

However the potential or apparent incompatibility between the visual and verbal components of the advertisement, the reader's recognition of compatibility between them increases his/her positive regard to accept the argument. Accordingly, there is a concession relation holding between the visual and verbal components of the advertisement. 


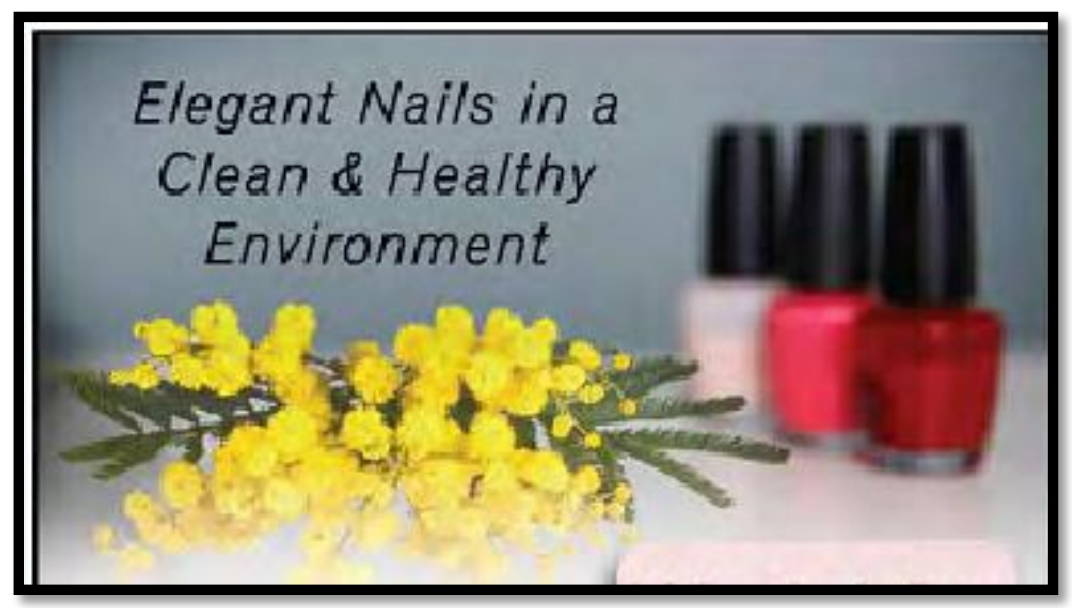

Figure (4)

On the verbal level, figure (4) is an advertisement for MIMOSA'S NAILS \& SPA. It reads “elegant nails in a clean $\&$ healthy environment". The producer wants to say that you can get your nails elegant in their clean and healthy SPA center. The similarity between elegant nails and clean and healthy environment represents the whole center and its services, thus, this advertisement is an example of metonym, an example of trope.

The advertisement consists of one noun phrase, "elegant nails in a clean \& healthy environment". This span presents intraclausal relation representing two spans: 1) elegant nails, and 2) in a clean \& healthy environment. Both spans are written in the same font and positioned as a single

( The effect of relations holding ...) Dr. AHMED ABDELHAY 
span; however, the first part is supposed to be more important and thus is a nucleus; on the other hand, the second part is less central, a satellite. Since comprehending the satellite increases the reader's ability to comprehend the nucleus, there is an evidence relation holding between the two parts of the span.

On the visual level, the advertisement presents the picture of nail polish bottles and a bunch of flowers. The producer uses the picture of a bunch of flowers as a reference to the healthy and clean environment. This reference is based on an underlying resemblance between clean and healthy environment and beautiful nails, thus there is a visual metaphor. There is an iconic relation flowers and clean environment; an indexical relation between flowers and healthy and clean environment; a symbolic relation between clean and healthy environment and elegant nails.

The visual part of the advertisement presents some additional details that help the reader identify the situation or some elements of the subject matter presented in the visual part, thus there is an elaboration relation holding between the verbal and visual parts of the advertisement. 


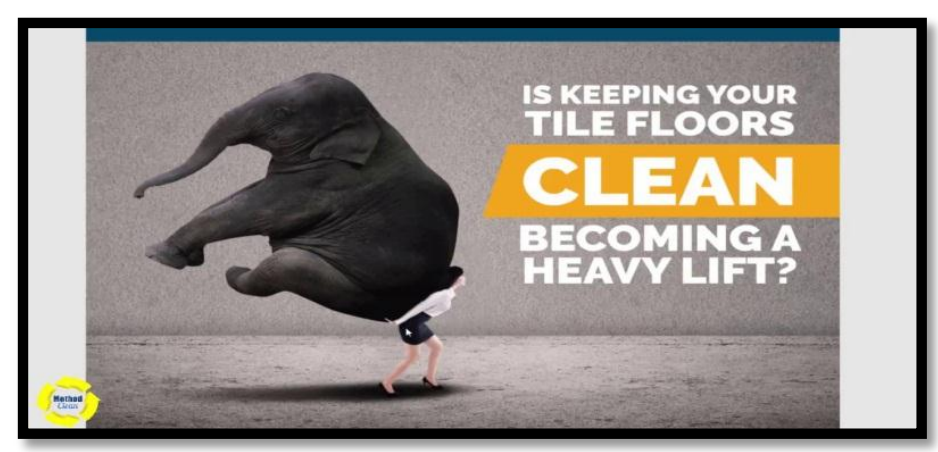

Figure (5)

Figure (5) is an advertisement for Method Clean, a company that offers cleaning products. It reads "IS KEEPING YOUR TILE FLOORS CLEAN BECOMING A HEAVY LIFT?" The producer used a rhetorical question, an example of trope, so as to make an assertion that it is tedious to clean your tile floors.

The advertisement consists of one span, IS KEEPING YOUR TILE FLOORS CLEAN BECOMING A HEAVY LIFT?, written in bold and positioned in a vertical order. However, the span could be judged to be less important and less central, thus it is a satellite. Despite the satellite could have caused a volitional action to be performed, a particular motivation is not known to the reader. In this way, there is a volitional cause relation.

( The effect of relations holding ...) Dr. AHMED ABDELHAY 
On the visual level, the advertisement employs a visual metaphor to say that the burden of keeping tile floors clean is as heavy as carrying a heavy elephant. There is an iconic representation of tile floors and a heavy thing; an indexical relation between cleaning and a heavy lift; a symbolic relation between an elephant and a heavy lift.

The visual part of the advertisement sets a framework in the subject matter within which the reader intended to interpret the verbal part, thus there is a circumstance relation holding between the verbal and the visual components of the advertisement.

\section{Conclusion and implications:}

According to Bateman (2014), elaboration or anchorage, on the one hand, is a relation showing specification or explanation. Specification is an illustration through which the text makes the image more specific and vice versa; explanation happens when the text paraphrases the image or vice versa. On the other hand, images anchor, extend, and illustrate texts making them clearer and loading culture and imagination. In other words, images make texts 
specific (or vice versa), specification, and paraphrase each other, explanation.

Secondly, extension is achieved when there is a similarity, contrast, or a complement between the image and the text. In the case of similarity, the content of both the text and the image is similar. A contrast relation, on the other hand, shows a contrast between the content of both the text and the image; and in a complement relation, the text and the image complement each other; however, both of them contribute different, yet semantically related, information.

To sum up, advertisers establish relations between verbal and parts of an advertisement to help readers recognize the significance of such combination. Verbal and visual rhetoric seem to be important components of advertising that advertisers tend to use to communicate their messages in a persuasive way. Many relations with different functions can hold between verbal and visual combinations. Some relations may explain or paraphrase the text and vice versa; others may have similar meaning; and others may contrast or complement each other. 


\section{References:}

Akpan, I. \& Akpan, E. \& Obukoadata, P. (2013). A Semiotic Deconstruction of Symbols in Print Advertising Contents: Implications for Consumers Purchase Decisions in Nigeria. Research on Humanities and Social Sciences, 3(13), 13-26.

Alozie, E. C. (2010). Advertising and Culture: Semiotic Analysis of Dominant Symbols Found in Nigerian Mass Media Advertising. Journal of Creative Communications, 5(1), 1-22.

Bateman, J. A. (2014). Text and image: A critical introduction to the visual/verbal divide. New York: Routledge.

Brierley, S. (1995). The advertising handbook. New York: Routledge.

Chandler, D. (2007). Semiotics: the basics. London and New York: Routledge.

Danesi, M. (2004). Messages, signs, and meanings: A basic textbook in semiotics and communication ( ${ }^{\text {rd }}$ ed.). Toronto: Canadian Scholars' Press Inc.

Dicerto S. (2018) On the Road to Multimodality: Semiotics. In: Multimodal Pragmatics and Translation. Palgrave Studies in Translating and Interpreting. Palgrave Macmillan, Cham. 
Džanić, M. (2013). The semiotics of contemporary advertising messages: decoding visuals. Jezikoslovlje, 14.2-3: 475-485.

Fletcher, W. (2010). Advertising: a very short introduction. New York: Oxford University Press.

Goodman, A. (2002). Why bad ads happen to good causes. Los Angeles: Cause Communication.

Kress, G \& van Leeuwen, T. (1996). Reading Images, the Grammar of Visual Design. London: Routledge.

Mann, W. C. \& Thompson, S. A. (1988). Rhetorical structure theory: toward a functional theory of text organization. Text, 8(3), 243-281.

McQuarrie, E. F. \& Mick, D. G. (2003). Visual and verbal rhetorical figures under directed processing versus incidental exposure to advertising. Journal of Consumer Research, 29, 579-587.

Norrick, N. R. (1981). Semiotic principles in semantic theory. Amsterdam: John Benjamins B.V.

Pritchard, W. T. (2000). A semiotic content analysis and exegesis of world wide web advertising: A multimethodological search for the legacy of early 20th century modern art movements and the contextual understanding of digital design. PhD thesis, Bowling Green State University. 
Sebeok, T. A. (2001). Signs: An introduction to semiotics $\left(2^{\text {nd }}\right.$ ed.). London: University of Toronto Press.

Taboada, M. \& Mann, W. C. (2006). Applications of rhetorical structure theory. Discourse studies, 15(1), 65-89.

Taboada, M. \& Stede, M. (2009). Introduction to RST rhetorical structure theory. Burnaby: Simon Fraser University.

Wang, K. Y. \& Peracchio, L. A. (2008). Reading pictures: understanding the stylistic properties of advertising images. In McQuarrie, E. F. \& Phillips, B. J. (eds.). Go figure: New directions in advertising rhetoric, (pp. 205-226). New York: M.E.Sahrp.

Yakin, H. S. M. \& Totu, A. (2014). The semiotic perspectives of peirce and Saussure: A brief comparative study. Social and behavioral sciences. 155: 4-8. 
تأثير الروابط بين المكونات اللفظية والمرئية في اللغة المستخدمة في الإعلانات

ملخص

تُعد اللغة هي وسيلة التواصل بين أفراد المجتمع. قد يلجأ الأفراد لاستخدام الكلمات والرموز للتعبير عن أفكارهم وآراءهم ولإرسال رسائل من أجل التواصل. كما أن المفردات والكلمات اللفظية تستخدم في التواصل، فهناك طرق أخرى غير لفظية (مرئية) للتواصل.وبمكن استخدام أيًا من المفردات اللفظية والمرئية أو كلاهما لتوصيل معنى معين أو إرسال رسالة معينة. يعتمد منتجوا الإعلانات على استخدام مزيج من اللغة اللفظية وغير اللفظية (المرئية) من أجل توصيل المعنى والتأثثر على القاريء. ويقوم منتجوا الإعلانات بإنثاء روابط بين المكونات اللفظية والمرئية من أجل تحقيق هدف معين. يهدف هذا البحث إلى دراسة العلاقة والروابط بين المكونات اللفظية والمصورة التي تستخدم في بعض الإعلانات المختارة. وتبين من نتائج البحث وجود علاقات ذات مدلول لغوي بين المكونات اللفظية والمرئية المستخدمة في الإعلانات وأن هذا المزيج من الوسائط المتعددة يُستخدم لتحقيق معنى معين وإحداث تأثير مخطط له من قبل المنتج

$$
\text { الإعلان من أجل إقناع القاريء بمحتوى الإعلان. }
$$

الكلمات المفتاحية: الروابط البلاغية - البلاغة اللفظية - البلاغة المرئية -

$$
\text { البلاغة - الإعلانات - الإقناع. }
$$

